\title{
Economic Effects of COVID-19 Pandemic and Potential Solutions
}

\author{
Nteka Nikoletta \\ Faculty of Economics, South-West University “Neofit Rilsky”, Blagoevgrad, Bulgaria \\ Email address: \\ nikolettanteka@gmail.com
}

To cite this article:

Nteka Nikoletta. Economic Effects of COVID-19 Pandemic and Potential Solutions. International Journal of Economics, Finance and Management Sciences. Vol. 9, No. 4, 2021, pp. 159-164. doi: 10.11648/j.ijefm.20210904.13

Received: June 14, 2021; Accepted: June 30, 2021; Published: August 13, 2021

\begin{abstract}
Background: The pandemic scenario has existed for many years as a possibility by health scientists but was never taken seriously. The arrival of the virus about a year ago caught the whole world unprepared. The inability to tackle the virus with any medication has led many governments to quarantine so that the health crisis can be alleviated. However, the existence of this crisis has turned into an economic crisis, as many companies have stopped operating and many people do not have the income they had in previous years. Purpose: The purpose of this article is to describe the COVID-19 pandemic crisis, to analyze its effects on the world economy, but also to propose solutions. Method: This article is conducted as a literature review. Results: COVID-19 pandemic has dramatically affected all aspects of world economy. Conclusion: The World Bank is an international financial institution that provides financial and technical assistance to developing countries for development projects with the stated goal of reducing poverty. Nevertheless, it has played an important role in this pandemic with the funding of many governments as the World Bank has developed a new strategy that focuses on eradicating extreme poverty and promoting shared prosperity in a sustainable way. It is committed to helping countries achieve these goals with proven solutions that incorporate WBG knowledge and financial development services.
\end{abstract}

Keywords: Pandemic, COVID-19, Crisis

\section{Introduction}

The new SARS-CoV2 COVID is known to cause COVID19 , which is an effectively infectious sickness that is spread from one individual to another through hacking, sniffling, respiratory beads or exhalation. Indications of COVID-19, which show up around 5 days after contamination, are identified with seasonal influenza (eg, fever and hack), yet additionally incorporate others, like sore throat, muscle hurts [1]. What's more, loss of taste or smell [2]. COVID-19 has a comparative clinical show and qualities to two known illnesses of serious intense respiratory parcel disorder: "SARS-CoV2" and Middle Eastern respiratory condition: "MERS" [3].

COVID circles among creatures and now and again can contaminate people. Undoubtedly, MERS, SARS-CoV2 and SARS-CoV2 can be credited to zoonotic transmission [4]. In any case, SARS-CoV2 is the just one with a potential pandemic [5]. Utilization of colorful well evolved creatures, for example, horseshoe bats, which incorporates an enormous pool of SARS-CoV2-related infections, improves the probability of new infections from creatures or related conditions [6]. The primary SARS-CoV2 contaminations were related with the fish market around there [7], which sells live and butchered bats, snakes, marmots, fowls, and bunny and deer instruments [8] introduced bats as a potential wellspring of SARS-CoV2, as the last has a comparable quality arrangement (up to $96.2 \%$ ) to COVID present in bats. $\mathrm{Be}$ that as it may, different creatures may likewise be regular hosts for SARS-CoV2. For instance, MERSCoV and SARSCoV2 can be sent to people from camels and felines, separately [1].

SARS-CoV2 was recognized in December 2019 and around 3 months after the fact, COVID-19 was proclaimed a pandemic by the [9]. As of May 30, 2020, the COVID-19 pandemic had spread to more than 5.9 million individuals in excess of 188 nations, bringing about in excess of 365,000 deaths [10] and a lockdown of $33 \%$ of the total populace [11]. As of now, no general treatment or immunization for COVID-19 has been created. Mainstream researchers, 
specialists, sanitation investigators and food industry experts are earnestly looking for data on the best way to deal with the pandemic, for example comprehension of transmission courses and improvement of treatment and immunizations. It is additionally essential to foster imaginative SARS-CoV2 symptomatic focuses for tainted individuals as well as for food, surfaces and the climate as a rule.

Throughout the long term, various nations of the world face different pandemics, yet the latest of all that influences the whole world local area is COVID-19 [9]. This new infection has placed the entire landmass of the world in a condition of difficulty, along these lines making the worldwide force of monetary nations unequipped for checking this infection. Since the episode of the COVID pandemic a couple of months prior, governments all throughout the planet have confronted the test of tracking down an enduring answer for this staggering infection. As of March 31, 2020, numerous individuals worldwide have passed on from COVID-19, the exceptionally infectious respiratory sickness brought about by the COVID. In excess of 178 nations/areas have been influenced, as per information aggregated by Johns Hopkins University.

\section{Literature Review}

\subsection{The Transformation of the Health Crisis into an Economic Crisis}

With the growth and development of the pandemic, the whole world entered a health crisis. Although at first many of the leaders disputed the problem, then as a result there were many cases in these countries. A typical example was the United States of America which is in the first place in cases and deaths from coronavirus.

The main way to deal with, or rather prevent, the virus since it began to spread was social alienation. This was a solution that was demanded all over the world. When the cases started to increase, the main way to achieve the reward and not to collapse the hospital care was the quarantine, which was also used in our country. A typical example of the collapse of the health system was Italy, which had many cases, which brought the national health system to a standstill and many sufferers were left helpless.

Another reason for slowing down the spread of the virus was to save time for scientists to carry out the necessary tests and find the right drugs for treatment and vaccine, so that the effects of the virus could be successfully treated. All these restrictive measures to deal with the health crisis have had the effect of increasing the impact on the economy. In this way the health crisis turned into an economic crisis.

The adverse effects of these developments are significant, including the immediate disruption of global supply chains, the weaker final demand for imported goods and services, and the wider regional decline in international tourism and business travel. Airlines stranded their planes and factories closed, resulting in a significant reduction in production. Many countries began to live in states of war in peacetime [12].

\subsection{Historical Data on Previous Pandemics and Health Crises}

As in this pandemic, so in previous ones, there is a common assumption that not all pandemics affect all social groups in the same way. Historical data from previous pandemics and other health crisis situations are particularly revealing. Social determinants of health, such as income, housing, and work, were associated with morbidity and mortality rates during the Spanish flu pandemics of 1918 and the seasonal H1N1 flu in 2009, with the most socially vulnerable groups performing worse. rates and poorer health outcomes. It is worth noting that Edgar Sydenstricker, in 1931, challenged the prevailing scientific view of the time about the social neutrality of the Spanish flu, presenting elaborate data that clearly showed the prevalence of influenza among the working class in America. In this light, and given that health inequalities have been deteriorating rather than improving in recent years, according to a recently published Marmot study of ten years, the exact impact of social health determinants on the development of the COVID-19 pandemic may still be underestimated. Fears of widening pre-existing and social, racial and economic health inequalities, in the long run, may be verified [12].

\subsection{The Impact of COVID-19 on the Global Economy}

The stun to the worldwide economy from COVID-19 was quicker and more serious than the worldwide monetary emergency of 2008 and surprisingly the Great Recession. It is seen that the financial exchanges imploded by half or more, the credit markets froze, enormous liquidations followed, while joblessness rates increased by over $10 \%$ and GDP shrank at a yearly pace of $10 \%$ or more. Be that as it may, everything required around three years to get to this point. In the current emergency, comparative gigantic macroeconomic and monetary outcomes were acknowledged in three weeks.

It is seen that it required just 15 days for the US securities exchange to sink (falling 20\% from its top), this is the quickest fall ever. Presently, markets have contracted by $35 \%$, credit markets have dominated and credit spreads (like those for garbage securities) have arrived at 2008 levels. Indeed, even major monetary organizations like Goldman Sachs, JP Morgan and Morgan Stanley, anticipate that We GDP should decrease at a yearly pace of $6 \%$ in the main quarter and by $24 \%$ to $30 \%$ in the second. US Treasury Secretary Steve Mnuchin cautioned that joblessness could transcend $20 \%$ (double the most elevated level during the monetary emergency) [13].

COVID-19 significantly affects the financial circumstance and incorporates:

a. Loss of talented and experienced specialists.

b. Reduced work supply.

c. Loss of key staff and volunteers which can prompt helpless association and an absence of help for reconciliation.

d. Causes neediness through the death toll of the biograppler. 
e. Reduce usefulness and the adverse consequence on monetary development.

Each component of total buyer interest, like capital uses, sends out, is in extraordinary free fall. While most independently employed reporters expect a V-molded drop with the yield falling forcefully by a quarter and afterward rapidly recuperating the following. From the above it turns out to be certain that the COVID-19 emergency is something different totally extraordinary. The progressing compression doesn't give off an impression of being $\mathrm{V}$ or $\mathrm{U}$ or $\mathrm{L}$ formed (a sharp twist followed by stagnation). All things being equal, it would appear that an I: an upward line addressing the monetary business sectors and the genuine falling economy.

The most potential country so far is Italy, which has especially solid financial binds with China. Northern Italy is the new Wuhan (the Chinese city where the COVID originally showed up). With its wellbeing framework overflowed, the Italian government hit the brakes, closing down the retail economy prompting the segregation of the whole country. All shops aside from drug stores and supermarkets were shut. Individuals have been and have been told to remain at home and can enter public places just for the vital shopping or driving to work. Numerous public and private obligation commitments, (for example, lease and interest installments) have been suspended. Italy attempted to hinder the monetary clock until the COVID vanished.

Then, despite the fact that Germany has had not many COVID deaths up until now, the quantity of diseases is ascending as quick as elsewhere. In light of the emergency, the German government presented a momentary work stipend and gave liberal credit help, assurances or assessment deferrals for grieved organizations. Public occasions the nation over have been dropped and understudies have been told to remain at home. Austria, as far as concerns its, has since a long time ago shut its boundary with Italy. Austrian schools, colleges and most shops have additionally shut. At first, France adopted a more loosened up strategy, however now it has additionally shut its schools, eateries and shops, as has Spain. Denmark, Poland and the Czech Republic have shut their lines with Germany.

In a meeting with BBC News on March 20, 2020 with Laura Jones, David Brown and Daniel Palumbo, it was proposed that the COVID flare-up, which started in China, had contaminated a great many people. Its multiplication has permitted organizations all throughout the planet to compute costs. They further focused on that the economy has been influenced through the accompanying:

\subsubsection{Stock Trades}

Enormous financial exchange shifts, where partakes in organizations are purchased and sold, can influence numerous ventures. The FTSE, Dow Jones Industrial Average and Nikkei have seen immense decays since the plague started on December 31. The Dow and the FTSE as of late saw the greatest one-day drop since 1987. Financial backers dread the spread of the COVID will hurt monetary development and that administration activity may not be sufficient to stop the decrease. Accordingly, national banks in numerous nations, including the United Kingdom, have cut loan costs. This ought to, in principle, make loaning less expensive and urge spending to support the economy. Worldwide business sectors additionally recuperated soon after the U.S. Senate vote on $\$ 2$ trillion (7 1.7 billion) to help laborers and organizations. Notwithstanding, a few examiners have cautioned that they could be unpredictable until the pandemic dies down. In the United States, the quantity of individuals applying for joblessness has arrived at a record high, denoting the finish of a time of development for one of the world's biggest economies.

\section{Travel Industry}

The movement business has endured harshly, with aircrafts closing down flights and travelers dropping work excursions and get-aways. Governments all throughout the planet have acquainted travel limitations with attempt to control the infection. The EU has restricted explorers outside the coalition for 30 days in an extraordinary move to seal its lines due to the COVID emergency. In the United States, the Trump organization has prohibited voyagers from European air terminals from entering the United States. UK travel industry specialists have likewise communicated worry about keeping Chinese vacationers at home. There were 415,000 visits from China to the UK in the one year to September 2019. Chinese voyagers additionally burn through three fold the amount of on a normal visit to the UK at 1.6 1,680 each.

\subsubsection{Consumers Store Food}

Grocery stores and online conveyance administrations have revealed a tremendous expansion sought after as clients store merchandise, for example, tissue, rice and squeezed orange as the pandemic develops.

\subsubsection{Lockdown Impacts Are Apparent}

To stop the spread of the COVID-19 plague, numerous nations all throughout the planet have started to execute exceptionally brutal measures. Nations and world capital have been seriously secured, bringing about the suspension of huge modern creation chains out and out. The European Space Agency has seen an emotional drop in contamination in the European skies.

\subsubsection{Factories in China Eased Back Down}

In China, where the COVID initially showed up, modern creation, deals and speculation all declined in the initial two months of the year, contrasted with a similar period in 2019. China represents $33 \%$ of development worldwide and is the biggest exporter of merchandise on the planet. Limitations have influenced the inventory chains of enormous organizations, for example, modern hardware producer JCB and automaker Nissan. All vehicle shops and vendors have announced falling interest. Vehicle deals in China, for instance, fell $86 \%$ in February. Most carmakers, like Tesla or Geely, presently sell vehicles online as clients avoid display areas.

\subsubsection{Even "More Secure" Investments Were Hit}

At the point when an emergency strikes, financial backers 
frequently decide on safer ventures. However, even the cost of gold succumbed to sometime in March, as financial backers dreaded a worldwide downturn.

Essentially, oil has tumbled to costs that didn't exist before June 2001.

Financial backers dread that the worldwide spread of the infection will additionally hit the worldwide economy and interest for oil. The cost of oil had effectively been influenced by a debate between OPEC, the gathering of oil makers and Russia. COVID has additionally scaled down the cost.

\subsubsection{Growth Is Set to Stop}

On the off chance that the economy develops, it by and large methods more riches and all the more new positions. It is estimated based on the rate change in GDP or the worth of labor and products created, generally over a time of a quarter of a year or a year. As indicated by the Organization for Economic Co-activity and Development (OECD), the worldwide economy will begin developing quickly from 2009 due to the COVID pestilence.

The research organization has estimate an increment of only $2.4 \%$ in 2020 , from $2.9 \%$ in November. He additionally said a "long haul and more serious" plague could split development to $1.5 \%$ by 2020 as industrial facilities shut down and laborers remain at home to attempt to control the [14].

\subsection{Black Swan Crisis}

The COVID-19 pandemic refers to a "Black Swan event". For most of us, this fact came out of nowhere. Everything was normal and suddenly the virus started affecting all parts of the world. It seemed to be a Black Swan event. Nassim Nicholas Taleb, a Lebanese-American scholar, made the idea famous in his 2007 book The Black Swan: The Impact of the Extremely Lean. Describes a Black Swan event that has the following three distinctive features:

(a) Rare, high-profile, difficult-to-predict, events that have an excessive impact and are beyond normal expectations;

(b) Facts whose probabilities are so small that they are difficult to calculate. and

(c) Facts and their causation that we tend to explain after the event.

Unbelievable events seem impossible when they are in the unknown or in the future. But after they happen, people try to rationalize them in their perception of the world. Experts discuss whether one had predicted such an event or why one could not.

Even if a pandemic is not unknown, it is important that the size, spread and impact of COVID-19 could have been predicted. The way it flooded most countries in the world, the pressure it exerted on the medical infrastructure and the savagery of its financial implications were perhaps unthinkable. It is in the realm of fantasy whether memories of the Spanish Influenza of the last century could or should have guided us to predict the nature of today's pandemic. Interestingly, a few months after the pandemic started, Taleb
[15] reportedly said that the COVID-19 pandemic was not a Black Swan event. it was a White Swan event, if it ever existed, because it was predictable.

It is quite obvious that when the present pandemic stops, there will be more debate as to whether it was indeed a Black Swan Event or something that was and is completely expected. While I have provocatively used "Black Swan" in the title of this paper, my goal here is not to get into an academic cleaner discussion about terminology. My aim is to take part in a futuristic conversation about how we can be better prepared and build resilience to deal with adverse events - not just a pandemic but any event that has a similar disproportionate impact - and here I would like to mention Søren Kierkegaard, a Danish philosopher of the early 19th century, who said: "Life can only be understood backwards, but must be lived forward."

\section{Conclusion}

The job of the World Health Organization, the Centers for Disease Control, including the spaces of correspondence to battle the pandemic, is inescapable. Various measures have been embraced by various nations to restrict the spread of COVID.

The African Development Bank has reported wellbeing and security measures to forestall the COVID from spreading to nations where it has a presence, remembering its central command for Abidjan. The actions incorporate teleworking, video conferencing rather than actual gatherings, the suspension of visits to the Bank's structures and the crossing out of all excursions, gatherings and meetings, until additional notification.

A few African states have forced broad limitations with an end goal to control the spread of the COVID. South Africa has pronounced a public calamity and reported a movement restriction from the most influenced nations, while Kenya has additionally forced clear travel limitations. The actions are an endeavor to forestall a significant scourge on a landmass with chronic weakness administrations. In any event 27 African nations have been influenced by the infection up until now. In Nigeria, all learning foundations were shut and representatives were approached to remain at home and play out the essential authoritative capacities from that point. Disappointment rates are still imposed 5 just like the case in all states and extra staff performing key undertakings like clinical staff, law requirement administrations were diminished to forestall the spread of the infection, cash and other fundamental things were given by legislative and nonlegislative associations, including houses of worship and corporate bodies. Exchange fairs, displays, films, carnivals and creatures and relaxation suppliers (inside and outside), extraordinary business sectors, arcades, gambling clubs, wagering and comparative offices are totally shut.

Failure rate alludes to the disappointment pace of something, like a thing or framework. We normally express it in disappointments per unit of time, that is, disappointments each hour, day, week, and so on [16]. 
Germany receives extraordinary measures to control the COVID pandemic. Administrative and state governments have taken a few intense measures to moderate the developing pace of COVID disease (COVID-19) in the country. The actions request exceptional limitations on open life in the country. In a public broadcast discourse, Chancellor Angela Merkel said the central government and the administrations of the 16 bureaucratic states had consented to close pointless organizations and public offices the nation over as a final desperate attempt to check the exceptionally infectious illness.

The Italian government has declared crisis measures to control the infection, which initially spread there in late February. Leader Giuseppe Conte has announced the entire of Italy a "red zone" which implies that individuals should remain at home separated from work and different crises. Public social events have been restricted and opportunity of development has been abridged. All homegrown games in the nation were suspended until 3 April. Football is serious for Italy. Police and fighters mind travelers leaving the primary train station in Milan, Italy. The public authority said the entire nation was a "red zone".

In Iran, public get-togethers, remembering Friday supplications for Tehran and other significant urban communities, were dropped. Schools have shut and cleaner teams have been shipped off sanitize trains, transports and get together zones, NPR's Peter Kenyon said. Iranian Foreign Minister Zawad Jarif composed on Twitter that "exacting careful steps are being executed, including airport regulation at takeoff entryways."

South Korea has energized individuals in urban communities the nation over to remain at home, a few workplaces have shut and numerous occasions have been delayed. Public schools were shut until March 22. The country's biggest flare-up was in the city of Daegu, which represents more than $3 / 4$ of cases.

In Spain, experts in many regions, like Madrid, the Basque Country and La Rioja, requested the conclusion, everything being equal, colleges and kindergartens for about fourteen days. Trips among Spain and Italy have been suspended and huge social affairs in the three districts are dropped. The Spanish La Liga football matches will occur before the arenas are unfilled for the following fourteen days. Spanish Health Minister Salvador Illa urged organizations to diminish working hours and make a trip and to help distant work.

The pandemic of COVID 2019 (COVID-19) carried wellbeing frameworks as far as possible, yet immediately turned into a danger to the whole world economy, on a scale far more prominent than the monetary period 200708 of the financial emergency. Strategy producers from big league salary nations reacted rapidly, submitting extraordinary measures of help to residents and organizations. The EU declared a "boundless" obligation to securing European economies through the sovereign and corporate obligation market, with the US Congress consenting to \$2 billion. Notwithstanding, such measures are not open to low-pay and center pay nations (LMICs), which will bear the weight of
COVID-19. Developing business sectors were among the first from which financial backers got away and have so far removed more than $\$ 83$ billion from them, the biggest capital stream at any point recorded. This restricts the credit accessible to governments and organizations, pushes down product costs and genuine monetary movement, and at last decreases medical services financial plans at whatever point limit is direly required.

The G20 nations imagined the two driving worldwide monetary establishments, the International Monetary Fund (IMF) and the World Bank, to assume a focal part in supporting these nations by going about as "monetary firemen". Fundamentally, lately, both have reported a bunch of instruments to address the impacts of the pandemic. However, is this the most ideal approach to accomplish enduring worldwide medical coverage? The IMF is reacting to crisis help demands from in excess of 80 nations and has given two progressions of crisis subsidizing. Like, up to $\$ 50$ billion in fast dispensing financing is accessible for LMICs, which don't have to have a full IMF program. In the mean time, nations can apply for calamity alleviation and trust alleviation and backing intended to help pandemics. This asset has about $\$ 400$ million accessible up until now and may increment further. Toward the start of April, just four nations had gotten support from any medium and from the IMF, the fundamental answer was something very similar: the stimulus for emergency stricken nations is to apply for typical mortgages, which albeit more adaptable in financing increment, as indicated by data, the measure of acquiring can reach up to $\$ 1$ trillion. These credits are dependent upon dubious change necessities that should be presented before the cash can be dispensed. Such conditions adversely affect the soundness of the populace since they incorporate inadequately planned strategy measures, for example, spending cuts, decrease in the number and pay rates of wellbeing and social laborers, debilitating of the labor force, security or advancement of privatizations.

The World Bank has reported a $\$ 14$ billion medical aid bundle and desires to develop it to $\$ 160$ billion throughout the following 15 months. Consequently, utilizing the Health, Nutrition and Population Division, with its involvement with the wellbeing area, the majority of this help ( $\$ 8$ billion) will be directed through the International Finance Corporation, the Bank's private area subsidizing. This arm has been picked notwithstanding the absence of mastery in setting up general wellbeing frameworks, and the amassed proof of terrible (and exorbitant) general wellbeing organizations.

World Bank (or IMF) advances will likewise trouble nations with extra obligation reimbursements that will keep on emptying cash out of wellbeing frameworks. The leftover $\$ 6$ billion is reserved for guaranteed essential consideration support. The World Bank is arranging new fast obtainment and approaches to mass market clinical supplies. Be that as it may, it is muddled whether this will fortify the general wellbeing frameworks he is at present battling with or, all things considered, reserve private wellbeing and overall the administrations they could get from it just as the truly 
necessary staff required in the general wellbeing framework. The last appears to be almost certain, for two reasons. In the first place, the $\$ 2$ billion International Finance Corporation will be dispensed through the Crisis Facility, which gives, entomb alia, credits to private medical care organizations. Second, World Bank President David Malpass clarified that his establishment's help would rely upon primary change arrangements ordering liberation (eg by advancing private wellbeing markets) or changing exchange [17].

\section{References}

[1] European Center for Disease Prevention and Control. (2020). Q \& A $\quad$ A $\quad$ COVID-19: https://www.ecdc.europa.eu/en/COVID-19/questions-answers

[2] Bienkov, A. (2020). If you've lost your sense of smell or taste, you could be a 'hidden carrier' of the coronavirus.

[3] Das's, U. N. (2020). Can bioactive lipids inactivate coronavirus (COVID-19)? Archives of Medical Research. doi: 10.1016/j.arcmed.2020.03.004.

[4] A. J. Rodriguez-Morales D. K. Bonilla-Aldana G. J. BalbinRamon A. A. Rabaan R. Sah A. Paniz-Mondolfi P. Pagliano S. Esposito. (2020). History is repeating itself: Probable zoonotic spillover as the cause of the 2019 novel Coronavirus Epidemic, Le, In Infezioni in Medicina, 28 (1), pp. 3-5.

[5] Mackenzie, J. S. \& Smith, D. W. (2020). COVID-19: A novel zoonotic disease caused by a coronavirus from China: What we know and what we don't. Microbiology Australia, 41 (1), б. 45. doi: 10.1071/ma20013.

[6] Cheng, V. C. C., Lau, S. K. P., Woo, P. C. Y. \& Kwok, Y. Y. (2007). Severe acute respiratory syndrome coronavirus as an agent of emerging and reemerging infection. Clinical Microbiology Reviews, 20 (4), pp. 660-694. doi: 10.1128/CMR.00023-07 American Society for Microbiology (ASM).

[7] Lu, J., Gu, J., Li, K., Xu, C., Su, W., Lai, Z., Zhou, D., Yu, C., Xu, B. \& Yang, Zu. (2020). COVID-19 outbreak associated with air conditioning in restaurant, Guangzhou, China, 2020. Emerging Infectious Diseases, 26 (7). doi: 10.3201/eid2607.200764.
[8] Jalava, K. (2020). first respiratory transmitted food borne outbreak? International Journal of Hygiene and Environmental Health (226), $\sigma . \quad 113490 . \quad$ doi: 10.1016/j.ijheh.2020.113490, Elsevier GmbH.

[9] WHO Director. (2020). General's opening remarks at the media briefing on COVID-19 - 15 April 2020.

[10] Dong, E., Du, H. \& Gardner, L. (2020). An interactive webbased dashboard to track COVID-19 in real time. The Lancet Infectious Diseases, 0 (0). doi: 10.1016/S14733099(20)30120-1. Lancet Publishing Group.

[11] Kaplan, J. Frias, L. \& McFall-Johnsen, M. (2020). Countries that are on lockdown because of coronavirus - Business Insider. Business Insider: https://www.businessinsider. com/countries-on-lockdown-coronavirus-italy-2020-3

[12] Vassilopoulos N. Giergo S. Panagiotopoulos E. (2020). Thesis: The future of national economies and the world economy after the Korona pandemic. Recovery from University of Patras, Messolonghi.

[13] Gabbatt, A. (2020). Steven Mnuchin warns coronavirus could bring 20\% unemployment.

[14] Abodunrin, O., Oloye, G. \& Adesola, B. (2020). CORONAVIRUS PANDEMIC AND ITS IMPLICATION ON GLOBAL ECONOMY. International Journal of Arts, Languages and Business Studies (IJALBS), 4, pp. 13 - 23.

[15] Taleb, N. N. (2007). The Black Swan: the impact of highly improbable. USA: Penguin Publishers. https://www.bloomberg.com/news/videos/2020-03-31/nassimtaleb-says-whiteswan-coronavirus-pandemic-was-preventablevideo; 2020.

[16] Market Business News. (2020). What is the failure rate? Definition and examples: https://marketbusinessnews.com/financial-glossary/failurerate/ (in Greek).

[17] Kentikelenis, A., Gabor, D., Ortiz, I., Stubbs, T., McKee, M. \& Stuckler, D. (2020). Softening the blow of the pandemic: will the International Monetary Fund and World Bank make things worse? The Lancet Global Health. doi: 10.1016/S2214109X(20)30135-2. 